\title{
Association of sleep disturbance with risk of cardiovascular disease and all-cause mortality in patients with new-onset type 2 diabetes: data from the Korean NHIS-HEALS
}

\author{
Young Choi ${ }^{1}$ and Jae Woo $\mathrm{Choi}^{2^{*}}$ (i)
}

\begin{abstract}
Background: Sleep disturbance has been significantly associated with the incidence of cardiovascular disease (CVD) in the general population. However, despite the common prevalence of sleep disturbance in patients with type 2 diabetes, its relationship with the risk of CVD remains unclear. Here, we have examined the association of sleep disturbance with the incidence of all CVD and all-cause mortality in patients with newly-diagnosed type 2 diabetes.

Methods: We used the Korean National Health Insurance Service-Health Screening Cohort data and included 36,058 patients with new-onset type 2 diabetes aged $\geq 40$ years between 2004 and 2007, along with follow-up examinations to 2013. We used the ICD-10 code to measure sleep disturbance as a primary diagnosis and the multivariable Cox proportional hazards regression models to estimate the adjusted hazard ratio (AHR) and 95\% confidence interval (Cl) of all CVD, coronary heart disease (CHD), stroke, and all-cause mortality.

Results: We identified 6897 cases of all CVD (CHD, $n=4138$; stroke, $n=2759)$ and 2890 events of all-cause mortality during a mean follow-up period of 7.0 years. Sleep disturbance was associated with an increased risk of All CVD (AHR, 1.24; 95\% Cl, 1.06-1.46), CHD events (AHR, 1.24; 95\% Cl, 1.00-1.53), and all-cause mortality (AHR, 1.47; 95\% $\mathrm{Cl}, 1.15-1.87)$ in patients with new-onset type 2 diabetes. Furthermore, women (AHR, 1.33; 95\% Cl, 1.06-1.67) and middle-aged adults (AHR, 1.29; $95 \% \mathrm{Cl}, 1.02-1.64)$ with sleep disturbance had a significantly increased risk of CVD than those without; contrarily, men (AHR, 1.45; 95\% Cl, 1.09-1.95) and older adults (AHR, 1.51; 95\% Cl, 1.15-1.99) with sleep disturbance were associated with a significantly increased risk of all-cause mortality than those without.
\end{abstract}

Conclusions: Our findings suggest that sleep disturbance is significantly associated with an increased risk of CVD and all-cause mortality in patients with new-onset type 2 diabetes.

Keywords: Mortality, Cardiovascular disease, Coronary heart disease, Sleep disturbance, Stroke, Type 2 diabetes

\section{Background}

There were approximately 463 million patients with diabetes globally in the year 2019, which may increase to 700 million by 2045 [1]. The global economic burden of

\footnotetext{
*Correspondence: jwchoi2695@hanmail.net

${ }^{2}$ College of Pharmacy, Yonsei Institute of Pharmaceutical Sciences, Yonsei University, 162-1 Songdo-Dong, Yeonsu-Gu, Incheon, South Korea

Full list of author information is available at the end of the article
}

treating diabetes was estimated to be 1.31 trillion USD/y, considering both the direct costs and production losses due to disease morbidity or premature mortality [2]. This outcome consequently indicated that diabetes has become a silent epidemic on a global scale and poses a serious health concern [3]. Despite the advantages of early diagnosis and improved treatment modalities, the risk of cardiovascular disease (CVD) in patients with type

c) The Author(s) 2020. This article is licensed under a Creative Commons Attribution 4.0 International License, which permits use, sharing, adaptation, distribution and reproduction in any medium or format, as long as you give appropriate credit to the original author(s) and the source, provide a link to the Creative Commons licence, and indicate if changes were made. The images or other third party material in this article are included in the article's Creative Commons licence, unless indicated otherwise in a credit line to the material. If material is not included in the article's Creative Commons licence and your intended use is not permitted by statutory regulation or exceeds the permitted use, you will need to obtain permission directly from the copyright holder. To view a copy of this licence, visit http://creativeco mmons.org/licenses/by/4.0/. The Creative Commons Public Domain Dedication waiver (http://creativecommons.org/publicdomain/ zero/1.0/) applies to the data made available in this article, unless otherwise stated in a credit line to the data. 
2 diabetes remains remarkably higher than in those without diabetes [4].

Globally, CVD is considered to be the leading cause of premature mortality and accounts for more than 330 million years of life lost per year [5]. In Korea, 62,947 deaths were attributed to CVD, which accounts for more than $21 \%$ of the total deaths in the year 2018 [6]. Considering the fact that type 2 diabetes increases the risk of CVD by more than two-fold $[7,8]$, along with the increasing number of patients with type 2 diabetes and the substantial economic burden of diabetes, it is imperative to investigate the modifiable factors associated with the risk of CVD in patients with type 2 diabetes [3].

Sleep is indispensable to human health and an individual typically spends approximately one-third of his/ her life sleeping. It is considered to be a lifestyle behavior that can significantly influence the incidence of CVD and death [9]. A recent global prospective cohort study reported a J-shaped association between the measured duration of total daily sleep and mortality and major cardiovascular events [10]. A number of meta-analyses also demonstrated that sleep problems such as excessive (short or long) sleep durations or poor sleep quality may increase the overall risk of CVD and all-cause mortality [11-15] and the results suggest that sleep management may be essential in preventing CVD.

Sleep disturbance is common in patients with type 2 diabetes [16] and a previous study reported the high prevalence of sleep dysfunction in patients with type 2 diabetes, and demonstrated that a high proportion (69\%) of type 2 diabetics had a Pittsburgh sleep quality index score $\geq 5$, suggesting reduced and disturbed sleep [17]. However, there is limited evidence on the association between sleep disturbance and the risk of incident CVD in patients with type 2 diabetes. Although a crosssectional study suggested that poor sleep quality is considered as a potential risk factor for CVD in 332 patients with type 2 diabetes [18], the findings only indicated a bidirectional association between sleep problems and CVD in patients with type 2 diabetes.

Therefore, we have examined the association of sleep disturbance with the incidence of all CVD, coronary heart disease (CHD), stroke, and all-cause mortality in patients with newly diagnosed type 2 diabetes using the nationwide population-based cohort data. Additionally, we have identified the association between sleep disturbance and risk of all CVD and all-cause mortality stratified by sex and age.

\section{Methods}

\section{Data and study sample}

We used the Korean National Health Insurance ServiceHealth Screening Cohort (NHIS-HEALS) data [19]. The
Korean NHIS operates an obligatory health insurance program and that covers approximately $97 \%$ of the entire Korean population. All subscribers aged between 40 and 79 years are required to undergo a standardized, biannual health examination. The sample of NHIS-HEALS was extracted by a simple random sampling method to develop a representative sample that included $10 \%$ (514,866 individuals) of all health screening participants between 2002 and 2003 and subsequently underwent follow-up examinations up to 2013. NHIS-HEALS included information regarding participant eligibility (e.g., sex, age, and socioeconomic variables), health examination results (questionnaires on health-related behavioral variables and results of laboratory measurements), and a medical history (outpatient, inpatients, and pharmacy visits) for all visits to medical facilities of cohort sample. The NHIS-HEALS also includes the death registration information (e.g., causes and dates of deaths) from Statistics Korea. We cleaned the NHIS-HEALS data using the following three categories: (1) missing data- the study included missing values of variables that were used as confounding factors in the analysis models; (2) noisy data- there no cases of data repetition or data with key-in error; (3) inconsistent data- there were no inconsistencies in our data.

Among the 513,268 individuals who were included in the study between the years 2004 and 2007, we eliminated study participants with diagnosed type 1 diabetes from 2002 to $2007(n=6629)$; additionally, we excluded those without type 2 diabetes to include only those with type 2 diabetes as study subjects between 2004 and 2007 $(\mathrm{n}=425,161)$. Type 2 diabetes was defined by the presence of any one of following criteria $(n=81,478)$ : (1) fasting blood glucose level $\geq 126 \mathrm{mg} / \mathrm{dL}$ ( $7 \mathrm{mmol} / \mathrm{L}$ ), (2) minimum 1 additional diagnosis of type 2 diabetes within 6 months following the initial date of the diagnosis under the International Classification of Diseases 10th Revision (ICD-10) codes (E11-E14), (3) prescription of antidiabetes medication. We eliminated patients diagnosed with type 2 diabetes between 2002 and 2003 to recruit those with new-onset type 2 diabetes $(n=40,914)$. Furthermore, we excluded those who had a history of CVD before being diagnosed with sleep disturbance to minimize reverse causality $(n=4506)$ and the final study subjects were 36,058 patients with new-onset type 2 diabetes (Additional file 1: Fig. S1).

\section{Measurement}

Outcome variable in this study was the presence of CVD and all-cause mortality. We used the ICD-10 codes as a primary diagnosis for CVD, which included CHD (I20-I25) and stroke (I60-I63). All-cause mortality was measured using the dates of mortality from the 
NHIS-HEALS database. The survival length was estimated in days, and all study participants underwent follow-up examination until the occurrence of either of the following three outcomes: incidence of CVD or mortality, withdrawal from the medical security system, or the end of 2013, whichever occurred first. We utilized sleep disturbance as independent variable and estimated the same using the G47 (sleep disorders) or F51 (sleep disorders not due to a substance or known physiological condition) under ICD-10 codes as a primary diagnosis [20].

Potential confounding factors in this study included sex, age, income level, area of residence, BP, BMI, fasting glucose, total cholesterol, physical activity, heavy alcohol consumption, smoking, family history of diabetes, and comorbidities. Sex, age, area of residence, and income level were measured using information from the year that included the index date. The index date was defined as initial diagnosis date of sleep disturbance following the diagnosis of type 2 diabetes. We used the initial date of diagnosing type 2 diabetes for those without sleep disturbance to define the same.

Age was classified to middle-aged adults (4064 years) and older adults ( $\geq 65$ years). Income level was classified as (1) low (<40th percentile), (2) middle (41st-80th percentile), or 3) high (81st-100th percentile). Area of residence was classified as metropolitan (capital), urban (areas with a population of $>1$ million), or rural (otherwise). Blood pressure (BP), body mass index (BMI), fasting glucose, total cholesterol, physical activity, heavy alcohol drinking, smoking, and family history of diabetes were identified through the data of a health screening closest to the index date. The recommendations of World Health Organization for Asian population were used to categorize study participants into five BMI groups: $<18.5 \mathrm{~kg} / \mathrm{m}^{2}$ (underweight), $18.5-$ $22.9 \mathrm{~kg} / \mathrm{m}^{2}$ (normal), $23.0-24.9 \mathrm{~kg} / \mathrm{m}^{2}$ (overweight), $25.0-29.9 \mathrm{~kg} / \mathrm{m}^{2}$ (class I obese), or $\geq 30 \mathrm{~kg} / \mathrm{m}^{2}$ (class II obese) [21]. Consuming $\geq 30 \mathrm{~g} /$ day of alcohol were defined as heavy alcohol consumption [22]. Physical activity was defined as exercising at least once a week. Smoking was categorized as non-smoking, ex-smoking, or currently smoking. Diastolic and systolic BP was measured after seating the individual for a minimum period of $5 \mathrm{~min}$. Blood samples were obtained after overnight fasting to estimate serum glucose, and total cholesterol. Comorbidities were measured through the screening before the index date using medical records; they consisted of hypertension (ICD-10: I10-I15), dyslipidemia (ICD-10: E78), chronic kidney disease (ICD-10: N18), depression (ICD-10: F32-F33), chronic obstructive pulmonary disease (ICD-10: J43-J44 [except J43.0]), and cancer (ICD-10: C00-C99).

\section{Statistical analysis}

Demographic and clinical characteristics in the study subjects were categorized according to sleep disturbance using a Pearson's Chi square test and an independent $t$ test. Data are indicated as number with percentage for categorical variables or as mean \pm standard deviation for continuous variables. CVD and all-cause mortality were estimated for each study participant from the index dates between 2004 and 2007 to end of the study period on December 31, 2013. We measured the sum of personyears for follow-up and calculated the incidence of CVD and all-cause mortality per 10,000 person-years.

This study estimated adjusted hazard ratio (AHR) and 95\% confidence interval $(\mathrm{CI})$ with regard to the association between sleep disturbance and incidence of CVD and all-cause of mortality using Cox proportional hazards regression models. First, we examined the effect of sleep disturbance on the incidence of all CVD, coronary heart disease, stroke, and all-cause mortality among patients having new-onset type 2 diabetes. Second, we analyzed the relationship between sleep disturbance and risk of all CVD and all-cause mortality, and classified the resulting data by sex and age. Extraction and statistical analyses of the data were performed using the SAS 9.4 (SAS Institute Inc., Cary, NC). Proportional hazards assumptions were assessed statistically and satisfied for all models.

\section{Results}

This study included 36,058 study subjects with newly diagnosed type 2 diabetes aged $\geq 40$ years and examined 6897 events of all CVD (CHD, $n=4138$; stroke, $n=2759$ ) and 2890 events of all-cause mortality during a mean follow-up period of $7.0 \pm 2.5$ years. Table 1 presents the general characteristics of study participants according to sleep disturbance. The proportions of women $(46.4 \%$ vs. $38.7 \%)$, older adults ( $43.4 \%$ vs. $24.6 \%)$, high income (32.6\% vs. 29.9\%), comorbidities (hypertension [56.7\% vs. $40.9 \%$ ], dyslipidemia [51.1\% vs. $26.4 \%$ ], depression [27.8\% vs. $7.2 \%$ ], chronic obstructive pulmonary disease [ $15.2 \%$ vs. $6.7 \%]$ and cancer $[17.0 \%$ vs. $7.2 \%]$ ) of individuals with sleep disturbance were significantly higher compared to those without sleep disturbance in patients with type 2 diabetes, respectively. However, those with sleep disturbances showed significantly lower levels of average systolic $(128.9 \mathrm{mmHg}$ vs. $131.1 \mathrm{mmHg})$ and diastolic $(79.8 \mathrm{mmHg}$ vs. $81.5 \mathrm{mmHg}) \mathrm{BP}$, fasting glucose $(114.2 \mathrm{mg} / \mathrm{dL}$ vs. $117.8 \mathrm{mg} / \mathrm{dL})$, and the proportions of current smoking (16.6\% vs. $22.3 \%)$, and physical activity $(33.1 \%$ vs. $41.3 \%)$ of people with sleep disturbance were significantly lower compared to than those without sleep disturbance among patients with type 2 diabetes, respectively. Missing data for each confounding factors among 
Table 1 General characteristics of study subjects according to sleep disturbance

\begin{tabular}{|c|c|c|c|c|c|c|}
\hline \multirow[t]{3}{*}{ Variables } & \multirow[t]{3}{*}{ Total } & \multicolumn{4}{|c|}{ Sleep disturbance } & \multirow[t]{3}{*}{$p$-value } \\
\hline & & \multicolumn{2}{|l|}{ Yes } & \multicolumn{2}{|l|}{ No } & \\
\hline & & $\mathbf{N}$ & $\%$ & $\mathrm{~N}$ & $\%$ & \\
\hline Total & 36,058 & 870 & 2.4 & 35,188 & 97.6 & \\
\hline Women & 14,030 & 404 & 46.4 & 13,626 & 38.7 & $<.001$ \\
\hline Age (years) & & & & & & $<.001$ \\
\hline $40-64$ & 27,009 & 492 & 56.6 & 26,517 & 75.4 & \\
\hline $65 \leq$ & 9049 & 378 & 43.4 & 8671 & 24.6 & \\
\hline BMI $\left(\mathrm{kg} / \mathrm{m}^{2}\right)$ & & & & & & $<.001$ \\
\hline$\leq 18.5$ & 614 & 23 & 2.6 & 591 & 1.7 & \\
\hline $18.5-23$ & 8985 & 253 & 29.1 & 8732 & 24.8 & \\
\hline $23-25$ & 8678 & 184 & 21.1 & 8494 & 24.1 & \\
\hline $25-30$ & 12,658 & 246 & 28.3 & 12,412 & 35.3 & \\
\hline$\geq 30$ & 1511 & 33 & 3.8 & 1478 & 4.2 & \\
\hline \multicolumn{7}{|l|}{$\mathrm{BP}(\mathrm{mmHg})$} \\
\hline Systolic & $131.1 \pm 17.5$ & 128.9 & 17.3 & 131.1 & 17.5 & $<.001$ \\
\hline Diastolic & $81.4 \pm 11.2$ & 79.8 & 11.1 & 81.5 & 11.2 & $<.001$ \\
\hline Fasting glucose (mg/dL) & $117.8 \pm 43.2$ & 114.2 & 48.9 & 117.8 & 43.1 & 0.044 \\
\hline Total cholesterol (mg/dL) & $203.1 \pm 39.7$ & 201.8 & 40.8 & 203.2 & 39.7 & 0.360 \\
\hline Family history of diabetes & 2218 & 50 & 5.7 & 2168 & 6.2 & 0.897 \\
\hline Current smoking & 8000 & 144 & 16.6 & 7856 & 22.3 & 0.002 \\
\hline Heavy alcohol drinking & 2034 & 36 & 4.1 & 1998 & 5.7 & 0.113 \\
\hline Physical activity & 14,825 & 288 & 33.1 & 14,537 & 41.3 & $<.001$ \\
\hline Income level & & & & & & 0.020 \\
\hline Low & 11,597 & 296 & 34.0 & 11,301 & 32.1 & \\
\hline Middle & 13,641 & 290 & 33.3 & 13,351 & 37.9 & \\
\hline High & 10,820 & 284 & 32.6 & 10,536 & 29.9 & \\
\hline Area of residence & & & & & & 0.341 \\
\hline Metropolitan & 5547 & 129 & 14.8 & 5418 & 15.4 & \\
\hline Urban & 9776 & 220 & 25.3 & 9556 & 27.2 & \\
\hline Rural & 20,735 & 521 & 59.9 & 20,214 & 57.4 & \\
\hline \multicolumn{7}{|l|}{ Comorbidities } \\
\hline Hypertension & 14,877 & 493 & 56.7 & 14,384 & 40.9 & $<.001$ \\
\hline Dyslipidemia & 9726 & 445 & 51.1 & 9281 & 26.4 & $<.001$ \\
\hline CKD & 177 & 8 & 0.9 & 169 & 0.5 & 0.067 \\
\hline Depression & 2776 & 242 & 27.8 & 2534 & 7.2 & $<.001$ \\
\hline COPD & 2488 & 132 & 15.2 & 2356 & 6.7 & $<.001$ \\
\hline Cancer & 2671 & 148 & 17.0 & 2523 & 7.2 & $<.001$ \\
\hline
\end{tabular}

BMI: body mass index; BP: blood pressure; CKD: chronic kidney disease; COPD: chronic obstructive pulmonary disease

Values are presented as mean \pm SD or $\mathrm{n}(\%)$

study subjects has been presented in Additional file 1: Table S2. The results for compete case analysis were similar to our main findings (Additional file 1: Table S3).

Table 2 shows the AHR and 95\% CI for incidence of CVD according to sleep disturbance in patients with new-onset type 2 diabetes. Following adjusting for sex, age, BMI, BP, fasting glucose, total cholesterol, family history of diabetes, smoking, heavy alcohol drinking, physical activity, income level, area of residence, and comorbidities, patients with sleep disturbance demonstrated a significantly increased risk of all CVD (AHR, 1.24; 95\% CI, 1.06-1.46) than those without sleep disturbance among patients with type 2 diabetes. Regarding the CVD subtypes, the risk of CHD (AHR, 1.24; 95\% CI, 1.00-1.53) increased significantly in patients with sleep disorders than those without, whereas study subjects 
Table 2 Association between sleep disturbance and incidence of CVD and all-cause mortality

\begin{tabular}{|c|c|c|c|c|c|c|c|c|}
\hline Variables & $\mathrm{N}$ & Events & Person-years & $\begin{array}{l}\text { The incidence of CVD or mortality } \\
\text { per } 10,000 \text { person-years }\end{array}$ & $H R^{a}$ & $95 \% \mathrm{Cl}$ & & $p$-value \\
\hline \multicolumn{9}{|c|}{ CVD events } \\
\hline \multicolumn{9}{|c|}{ Sleep disturbance } \\
\hline No & 35,188 & 6694 & 247,987 & 269.9 & 1.00 & & & \\
\hline Yes & 870 & 203 & 5075 & 400.0 & 1.24 & 1.06 & 1.46 & 0.009 \\
\hline \multicolumn{9}{|c|}{ CHD events } \\
\hline \multicolumn{9}{|c|}{ Sleep disturbance } \\
\hline No & 35,188 & 4018 & 247,987 & 162.0 & 1.00 & & & \\
\hline Yes & 870 & 120 & 5075 & 236.5 & 1.24 & 1.00 & 1.53 & 0.049 \\
\hline \multicolumn{9}{|c|}{ Stroke events } \\
\hline \multicolumn{9}{|c|}{ Sleep disturbance } \\
\hline No & 35,188 & 2676 & 247,987 & 107.9 & 1.00 & & & \\
\hline Yes & 870 & 83 & 5075 & 163.5 & 1.26 & 0.98 & 1.63 & 0.077 \\
\hline \multicolumn{9}{|c|}{ All-cause mortality } \\
\hline \multicolumn{9}{|c|}{ Sleep disturbance } \\
\hline No & 35,188 & 2768 & 247,987 & 111.6 & 1.00 & & & \\
\hline Yes & 870 & 122 & 5075 & 240.4 & 1.47 & 1.15 & 1.87 & 0.002 \\
\hline
\end{tabular}

with sleep disturbances was not significantly associated with the higher risk of stroke than those without sleep disturbances (AHR, 1.26; 95\% CI, 0.98-1.63) in patients with type 2 diabetes. Patients with sleep disturbance were associated with increased risk of all-cause mortality significantly (AHR, 1.47; 95\% CI, 1.15-1.87) than those without sleep disturbance among patients with type 2 diabetes.

Figure 1 shows the results for association between sleep disturbance and incidence of CVD and all-cause mortality according to sex and age. In patients with type 2 diabetes, women (AHR, 1.33; 95\% CI, 1.06-1.67) and middle-aged adults (AHR, 1.29; 95\% CI, 1.02-1.64) with sleep disturbance showed a significantly higher risk of CVD than those without sleep disturbance; however, the risk of all-cause mortality increased significantly in men (AHR, 1.45; 95\% CI, 1.09-1.95) and older adults (AHR, 1.51; 95\% CI, 1.15-1.99) with sleep disorders than those without sleep disturbance.

\section{Discussion}

Sleep disturbance was associated with an increased risk for all CVD and CHD events, along with all-cause mortality in patients with new-onset type 2 diabetes. In patients with type 2 diabetes, women and middle-aged adults with sleep disturbance showed a significantly higher risk of CVD than those without, whereas the risk of all-cause mortality significantly increased in men and older adults with sleep disturbance than those without sleep disturbance.

Despite the presence of a growing amount of evidence regarding the relationship between sleep disturbances and CVD, most of these studies have primarily focused on a population of individuals with a normal glucose tolerance. Additionally, most prior studies have utilized sleep duration as the only measure of sleep. However, a more recent evidence demonstrated the importance of studying parameters of sleep other than sleep duration $[23,24]$. Our study differs from previous studies by investigating the correlation between sleep disturbance and CVD risk in type 2 diabetes.

Our findings indicated that sleep disturbance was associated with a higher risk of CVD in patients with type 2 diabetes, which was consistent with the outcomes of previous studies [18]. Sleep disturbance could activate the autonomic nervous system and promote the secretion of catecholamine, which is a well-known risk factor for CVD [25]. Furthermore, sleep disturbance may also activate pro-inflammatory transcription factors such as nuclear factor kappa B (NF-kB), followed by elevating the expression of adhesion molecules (such as ICAM-1, VCAM-1 and selectins) and pro-inflammatory mediators (such as TNF- $\alpha$, IL-6 and IL-8). Subsequently, it may activate numerous endothelial cells and inflammatory cells, which may result in endothelial dysfunction. Endothelial dysfunction considerably influences CVD incidence [26]. 


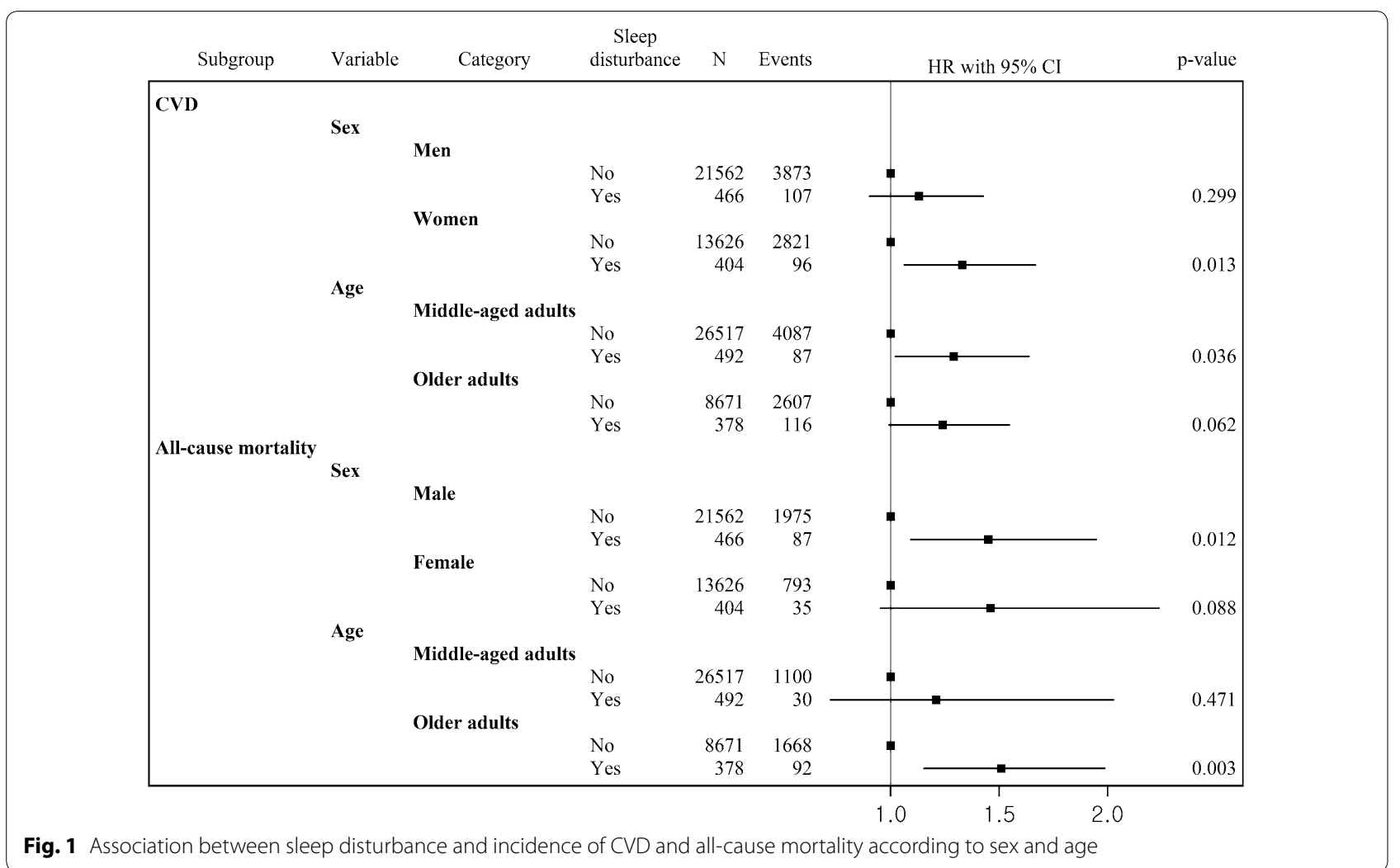

Obstructive sleep apnea is frequently observed in cases of metabolic syndrome [27] and it is one of the mechanisms that increase the risk of new-onset atrial fibrillation in obese individuals [28]. Divergence from the recommended 7 to $8 \mathrm{~h}$ of sleep is associated with a higher risk of mortality and cardiovascular events. Longer duration of sleep may be more associated with adverse outcomes compared with shorter sleep durations [11], concurrently, individual and coexisting symptoms of insomnia are independent risk factors for CVD incidence, particularly in young adults or adults without hypertension [29].

Sleep disturbance and all-cause mortality were significantly associated with each other in general population. Previously, a study demonstrated that individuals who had difficulty in falling asleep had $28 \%$ greater risk of all-cause mortality [30]. A meta-analysis study revealed the correlation between obstructive sleep apnea and an increased risk of all-cause mortality [31]. Our findings further validated those reported previously by extending the findings to patients with type 2 diabetes.

Our findings showed that sleep disturbance was associated with higher risk of coronary heart disease and not related to stroke. Concerning stroke, our findings are in the context of a literature that has shown conflicting results-although several studies indicated a significant association of a short sleep duration [32] and sleep apnea [33] with stroke, a study indicated the presence of a non-significant association between sleep disturbance and stroke [34]. Further research is needed to explore the association between sleep disturbance and stroke in type 2 diabetes.

Our findings suggested that sleep disturbance was associated with higher risk of all-cause mortality in men and older adults with type 2 diabetes, which is consistent with previous study findings $[35,36]$. However, this study revealed that sleep disturbance was associated with higher risk of all CVD in men and older adults with type 2 diabetes, which is not in line with previous studies. Sabanayagam and Shankar implied that excessively short or long sleep durations were associated with a higher risk of CVD in men, women, middle-aged and older adults, respectively [32]. Amagai et al. suggested that men who slept for fewer than $6 \mathrm{~h}$ a day were at an increased risk of CVD [37]. Our results implied that the association between sleep problems and all CVD according to age and sex among patients with type 2 diabetes was different from that of the general population and further research would be needed to examine these differences.

Our study has several potential limitations. First, we could not evaluate the association between subtypes of sleep disturbance and CVD and mortality because of limited data (Additional file 1: Table S1). Additionally, 
we could not assess more sleep-related factors including sleep duration, sleep depth, sleep timing, and degree of sleep disturbance since we used secondary data. Future research is warranted to explore CVD and mortality risk according to the subtypes and specific characteristics of sleep disturbance using adequate data. Second, although we excluded subjects diagnosed with CVD before being diagnosed with sleep disturbance, there may have been cases of reverse causality. Third, diagnosis of type 2 diabetes, sleep disturbance, comorbidities, and cardiovascular disease was identified according to ICD-10 codes of the NHIS claims database without reviewing the detailed clinical charts. The misclassification based on ICD-10 codes may have potentially affected our findings. Fourth, although the results of a compete case analysis were similar to our main findings, the missing data may potentially influence our findings. Fifth, biomarkers such as catecholamine, nuclear factor kappa B were not considered in this study due to the lack of pertinent data. Further studies on the association between sleep disturbance and CVD in patients with type 2 diabetes need to incorporate these biomarkers. Finally, we only included participants from the Korean population. Therefore, further investigation is needed to verify that our findings can be applied to individuals of other ethnicities.

\section{Conclusions}

This is possibly the first study to explore the association between sleep disturbance and risk of CVD and all-cause mortality in patients with new-onset type 2 diabetes. This study verified the significant association between sleep disturbance and an increased risk of CVD and mortality among patients with new-onset type 2 diabetes. Our results have implied the need for a more scrupulous investigation and appropriate management of sleep disturbance in the patients with type 2 diabetes to partly prevent the incidence of CVD events and premature mortality.

\section{Supplementary information}

Supplementary information accompanies this paper at https://doi. org/10.1186/s12933-020-01032-5.

Additional file 1: Figure S1. Flow chart of the study participants. Table S1. The number of incidence of CVD and all-cause mortality according to subtypes of sleep disturbance. Table S2. The number of missing values for potential confounding factors in this study. Table S3. Association between sleep disturbance and incidence of CVD and all-cause mortality in subjects with complete information for confounding factors.

\section{Abbreviations}

CVD: Cardiovascular disease; NHIS-HEALS: National Health Insurance ServiceHealth Screening Cohort; ICD-10: The International Classification of Diseases 10th Revision; BP: Blood pressure; BMI: Body mass index; AHR: Adjusted hazard ratio; Cl: Confidence interval.

\section{Acknowledgements}

Not applicable.

\section{Authors' contributions}

YC and JWC designed the study. YC and JWC performed the literature review and interpretation for data analysis. YC and JWC analyzed the data. YC and JWC wrote the draft. Both authors read and approved the final manuscript.

\section{Funding}

This work was supported by the Yonsei University Research Fund (Post Doc. Researcher Supporting Program) of 2019 [2019-12-0129].

Availability of data and materials

Data may be obtained from a third party and are not publicly available

\section{Ethics approval and consent to participate}

Since our study used administrative cohort data, this study was exempt from ethical approval from Yonsei University Institutional Review Board. The requirement for informed consent was waived as the NHIS-HEALS database was constructed after anonymization according to strict confidentiality guidelines.

\section{Consent for publication}

Not applicable.

\section{Competing interests}

The authors declare that they have no competing interests.

\section{Author details}

${ }^{1}$ Department of Health Care Management, Catholic University of Pusan, 57 Oryundae-ro, Geumjeong-gu, Busan, South Korea. ${ }^{2}$ College of Pharmacy, Yonsei Institute of Pharmaceutical Sciences, Yonsei University, 162-1 Songdo-Dong, Yeonsu-Gu, Incheon, South Korea.

Received: 19 February 2020 Accepted: 5 May 2020

Published online: 13 May 2020

\section{References}

1. Saeedi P, Petersohn I, Salpea P, Malanda B, Karuranga S, Unwin N, et al. Global and regional diabetes prevalence estimates for 2019 and projections for 2030 and 2045: results from the International Diabetes Federation Diabetes Atlas, 9(th) edition. Diabetes Res Clin Pract. 2019;157:107843.

2. Bommer C, Sagalova V, Heesemann E, Manne-Goehler J, Atun R, Barnighausen T, et al. Global economic burden of diabetes in adults: projections from 2015 to 2030. Diabetes Care. 2018:41(5):963-70.

3. Zheng Y, Ley SH, Hu FB. Global aetiology and epidemiology of type 2 diabetes mellitus and its complications. Nat Rev Endocrinol. 2018;14(2):88-98.

4. Cavender MA, Steg PG, Smith SC Jr, Eagle K, Ohman EM, Goto S, et al. Impact of diabetes mellitus on hospitalization for heart failure, cardiovascular events, and death: outcomes at 4 years from the reduction of atherothrombosis for continued health (REACH) Registry. Circulation. 2015;132(10):923-31.

5. Collaborators GBDCoD. Global, regional, and national age-sex-specific mortality for 282 causes of death in 195 countries and territories, 1980-2017: a systematic analysis for the Global Burden of Disease Study 2017. Lancet. 2018:392(10159):1736-88.

6. Statistics Korea. 2018 Statistics for causes of deaths in Korea: Statistics Korea; 2019. https://www.kostat.go.kr/portal/korea/kor_nw/1/6/2/ index.board? bmode $=$ read $\& b S e q=\& a S e q=377606 \&$ page $\mathrm{No}=1 \& \mathrm{rowNu}$ $m=10 \&$ navCount $=10 \&$ currPg $=\&$ searchlnfo $=\&$ Target $=$ title\&sTxt $=$

7. Muilwijk M, Ho F, Waddell H, Sillars A, Welsh P, lliodromiti S, et al. Contribution of type 2 diabetes to all-cause mortality, cardiovascular disease incidence and cancer incidence in white Europeans and South Asians: findings from the UK Biobank population-based cohort study. BMJ Open Diabetes Res Care. 2019;7(1):e000765. 
8. Laakso M. Cardiovascular disease in type 2 diabetes from population to man to mechanisms: the Kelly West Award Lecture 2008. Diabetes Care. 2010;33(2):442-9.

9. St-Onge MP, Grandner MA, Brown D, Conroy MB, Jean-Louis G, Coons $M$, et al. Sleep duration and quality: impact on lifestyle behaviors and cardiometabolic health: a scientific statement from the American Heart Association. Circulation. 2016;134(18):e367-86.

10. Wang C, Bangdiwala SI, Rangarajan S, Lear SA, AlHabib KF, Mohan V, et al. Association of estimated sleep duration and naps with mortality and cardiovascular events: a study of 116632 people from 21 countries. Eur Heart J. 2019;40(20):1620-9.

11. Kwok CS, Kontopantelis E, Kuligowski G, Gray M, Muhyaldeen A, Gale $C P$, et al. Self-reported sleep duration and quality and cardiovascular disease and mortality: a dose-response meta-analysis. J Am Heart Assoc. 2018;7(15):e008552

12. Krittanawong C, Tunhasiriwet A, Wang Z, Zhang HJ, Farrell AM, Chirapongsathorn $S$, et al. Association between short and long sleep durations and cardiovascular outcomes: a systematic review and metaanalysis. Eur Heart J-Acute Ca. 2019;8(8):762-70.

13. Yin J, Jin X, Shan Z, Li S, Huang H, Li P, et al. Relationship of sleep duration with All-cause mortality and cardiovascular events: a systematic review and dose-response meta-analysis of prospective cohort studies. J Am Heart Assoc. 2017;6(9):005947.

14. Cappuccio FP, Cooper D, D’Elia L, Strazzullo P, Miller MA. Sleep duration predicts cardiovascular outcomes: a systematic review and meta-analysis of prospective studies. Eur Heart J. 2011;32(12):1484-92.

15. Ge L, Guyatt G, Tian J, Pan B, Chang Y, Chen Y, et al. Insomnia and risk of mortality from all-cause, cardiovascular disease, and cancer: systematic review and meta-analysis of prospective cohort studies. Sleep Med Rev. 2019;48:101215.

16. Brouwer A, van Raalte DH, Rutters F, Elders PJM, Snoek FJ, Beekman ATF et al. Sleep and HbA1c in patients with type 2 diabetes: which sleep characteristics matter most? Diabetes Care. 2020;43(1):235-43.

17. Rajendran A, Parthsarathy S, Tamilselvan B, Seshadri KG, Shuaib M. Prevalence and correlates of disordered sleep in southeast Asian Indians with type 2 diabetes. Diabetes Metab J. 2012;36(1):70-6.

18. Meng LL, Tang YZ, Ni CL, Yang M, Song HN, Wang G, et al. Impact of inflammatory markers on the relationship between sleep quality and incident cardiovascular events in type 2 diabetes. J Diabetes Complic. 2015:29(7):882-6.

19. Seong SC, Kim YY, Park SK, Khang YH, Kim HC, Park JH, et al. Cohort profile: the National Health Insurance Service-National Health Screening Cohort (NHIS-HEALS) in Korea. BMJ Open. 2017;7(9):e016640.

20. Seo HM, Kim TL, Kim JS. The risk of alopecia areata and other related autoimmune diseases in patients with sleep disorders: a Korean populationbased retrospective cohort study. Sleep. 2018;41(9):zsy111.

21. Consultation WHOE. Appropriate body-mass index for Asian populations and its implications for policy and intervention strategies. Lancet. 2004;363(9403):157-63.

22. Agarwal DP. Cardioprotective effects of light-moderate consumption of alcohol: a review of putative mechanisms. Alcohol Alcohol. 2002;37(5):409-15.

23. Troxel WM, Buysse DJ, Matthews KA, Kip KE, Strollo PJ, Hall M, et al. Sleep symptoms predict the development of the metabolic syndrome. Sleep. 2010;33(12):1633-40.
24. Grandner MA, Patel NP, Gehrman PR, Xie D, Sha D, Weaver T, et al. Who gets the best sleep? Ethnic and socioeconomic factors related to sleep complaints. Sleep Med. 2010;11(5):470-8.

25. Mullington JM, Haack M, Toth M, Serrador JM, Meier-Ewert HK. Cardiovascular, inflammatory, and metabolic consequences of sleep deprivation. Prog Cardiovasc Dis. 2009;51(4):294-302.

26. Ryan S, Taylor CT, McNicholas WT. Systemic inflammation: a key factor in the pathogenesis of cardiovascular complications in obstructive sleep apnoea syndrome? Thorax. 2009;64(7):631-6.

27. Tuttolomondo A, Petta S, Casuccio A, Maida C, Corte VD, Daidone M, et al. Reactive hyperemia index $(\mathrm{RHI})$ and cognitive performance indexes are associated with histologic markers of liver disease in subjects with non-alcoholic fatty liver disease (NAFLD): a case control study. Cardiovasc Diabet. 2018;17(1):28

28. Kim YG, Han KD, Choi Jl, Boo KY, Kim DY, Oh SK, et al. The impact of body weight and diabetes on new-onset atrial fibrillation: a nationwide population based study. Cardiovasc Diabetol. 2019;18(1):128.

29. Zheng B, Yu CQ, Lv J, Guo Y, Bian Z, Zhou M, et al. Insomnia symptoms and risk of cardiovascular diseases among 0.5 million adults A 10-year cohort. Neurology. 2019;93(23):E2110-20.

30. Garfield V, Joshi R, Garcia-Hernandez J, Tillin T, Chaturvedi N. The relationship between sleep quality and all-cause, CVD and cancer mortality: the Southall and Brent REvisited study (SABRE). Sleep Med. 2019;60:230-5.

31. Xie C, Zhu R, Tian Y, Wang K. Association of obstructive sleep apnoea with the risk of vascular outcomes and all-cause mortality: a meta-analysis. BMJ Open. 2017;7(12):e013983.

32. Sabanayagam C, Shankar A. Sleep duration and cardiovascular disease: results from the National Health Interview Survey. Sleep. 2010;33(8):1037-42.

33. Redline S, Yenokyan G, Gottlieb DJ, Shahar E, O'Connor GT, Resnick HE, et al. Obstructive sleep apnea-hypopnea and incident stroke: the sleep heart health study. Am J Respir Crit Care Med. 2010;182(2):269-77.

34. Grandner MA, Jackson NJ, Pak VM, Gehrman PR. Sleep disturbance is associated with cardiovascular and metabolic disorders. J Sleep Res. 2012;21(4):427-33.

35. Rod NH, Vahtera J, Westerlund $H$, Kivimaki M, Zins M, Goldberg M, et al. Sleep disturbances and cause-specific mortality: results from the GAZEL cohort study. Am J Epidemiol. 2011;173(3):300-9.

36. Sterniczuk R, Theou O, Rusak B, Rockwood K. Sleep disturbance is associated with incident dementia and mortality. Curr Alzheimer Res. 2013;10(7):767-75.

37. Amagai Y, Ishikawa S, Gotoh T, Kayaba K, Nakamura Y, Kajii E. Sleep duration and incidence of cardiovascular events in a Japanese population: the Jichi Medical School cohort study. J Epidemiol/Japan Epidemiol Assoc. 2010;20(2):106-10.

\section{Publisher's Note}

Springer Nature remains neutral with regard to jurisdictional claims in published maps and institutional affiliations.

Ready to submit your research? Choose BMC and benefit from

- fast, convenient online submission

- thorough peer review by experienced researchers in your field

- rapid publication on acceptance

- support for research data, including large and complex data types

- gold Open Access which fosters wider collaboration and increased citations

- maximum visibility for your research: over 100M website views per year

At BMC, research is always in progress.

Learn more biomedcentral.com/submissions 